Article

\title{
Beef Consumers Behaviour and Preferences-The Case of Portugal
}

\author{
Teresa Paiva ${ }^{1,2,3, *(\mathbb{C}}$, Telma A. Jacinto ${ }^{1}\left(\mathbb{D}\right.$, Mafalda Cruz Sarraguça ${ }^{4}\left(\mathbb{D}\right.$ and Paula Coutinho ${ }^{1,5}(\mathbb{D}$ \\ 1 Center of Potential and Innovation of Natural Resources, Polytechnic Institute of Guarda, \\ 6300-559 Guarda, Portugal; telmajacinto@ipg.pt (T.A.J.); coutinho@ipg.pt (P.C.) \\ 2 Technological and Management School, CI\&DEI, Polytechnic Institute of Guarda, 6300-559 Guarda, Portugal \\ 3 Research Centre in Business Sciences, University of Beira Interior, 6200-609 Covilhã, Portugal \\ 4 LAQV-REQUIMTE, Departamento de Ciências Químicas, Faculdade de Farmácia, Universidade do Porto, \\ 4050-313 Porto, Portugal; mafalda.cruz@ff.up.pt \\ 5 Health Sciences Research Centre, University of Beira Interior (CICS-UBI), Avenida Infante D. Henrique, \\ 6200-506 Covilhã, Portugal \\ * Correspondence: tpaiva@ipg.pt
}

check for updates

Citation: Paiva, T.; Jacinto, T.A.; Sarraguça, M.C.; Coutinho, P. Beef Consumers Behaviour and Preferences-The Case of Portugal. Sustainability 2022, 14, 2358. https://doi.org/10.3390/su14042358

Academic Editor:

Manuela Vega-Zamora

Received: 2 January 2022

Accepted: 15 February 2022

Published: 18 February 2022

Publisher's Note: MDPI stays neutral with regard to jurisdictional claims in published maps and institutional affiliations.

Copyright: (c) 2022 by the authors. Licensee MDPI, Basel, Switzerland. This article is an open access article distributed under the terms and conditions of the Creative Commons Attribution (CC BY) license (https:// creativecommons.org/licenses/by/ $4.0 /)$.

\begin{abstract}
Meat consumption is estimated to increase worldwide, mostly because of the increase in population. Further, this increase in meat consumption will ultimately affect the environment and aggravate climate change. Herein, consumers' behaviour was studied to understand if consumers would consider a change in their dietary habits by choosing beef from the Portuguese autochthonous bovine breed or even reducing their meat intake for environmental reasons. In 2021, a survey was conducted online and in some food sales outlets in Portugal. Therefore, data collected from the 491 participants were analysed with the aim of assessing the Portuguese consumer behaviour and preferences on beef. Firstly, we conducted a descriptive analysis. Then, factor analysis was performed by principal component analysis. Finally, by cluster analysis, we attempted to identify a group of consumers with different behaviours into specific categories. Although it was not possible to segregate consumers into different categories, most of the respondents agree that meat consumption harms the environment; however, just $30.6 \%$ are willing to reduce meat consumption due to environmental reasons. As for the concerns for animal welfare, respondents between the age of 23 and 49 years seem to have a greater concern towards animal welfare. To value autochthonous bovine Jarmelista meat, it is fundamental to implement a concerted communication between suppliers and producers to value Jarmelista beef. Furthermore, it is also important that regional governmental institutions support local producers not only for financial support but also to create strategies to protect the breed from extinction.
\end{abstract}

Keywords: beef; Portuguese consumer; consumer preferences; sustainable production; bovine

\section{Introduction}

Tendencies in beef consumption behaviour are estimated to grow between 2019 and 2024. This occurs because of the population growth and rising incomes in developed countries [1], although there has been a shift from beef to poultry consumption. Changing dietary habits in a Western diet, from eating meat to more plant-based foods, is an environmentally impacting mitigation measure, which shows a significant difference in how people choose to eat [2]. Sustainable consumption is presently a consumer trend in different goods and particularly in food. Consumers seek food that has a sustainable component that varies between their ecological production, food processing, packaging, and waste residues. Biological food is a growing trend $[3,4]$ and in Europe is reaching a mature market status [5], and meat is the third most requested type of biological food [6]. Biological food in Portugal is becoming more appealing to consumers but in terms of beef production is not well developed yet since it seems that even the youngest do not express intentions or 
recognise reasons to change their meat consumption habits [7]. There is, although, a market appreciation of the autochthonous breeds, as they have been regarded as a high-quality product [8].

A consumer behaviour study aims to explain the why, what, when, and how the consumer buys a product or a brand [9]. Additionally, it demonstrates how people make decisions about what they buy. This is called the decision process [10]. However, this purchase process and its different phases have many conditions and variants that lead to almost different consumer decision-making [11]. This process leads consumers to consider the information they have about the products or services, influenced by their cultural and family environment, so that, according to their past experiences, lifestyle, perception, motivation, and personality, they transform them in decision making through a predisposition and purchase intention and its effective behaviour [12] overcoming all possible barriers and situations that may still determine the purchasing and consumption behaviour. The roles of all emotional influences during purchasing decision-making have been carefully investigated and often undermine the "rational side" [12]. Consumer attitudes (Attitude refers to a person's feelings towards an object, person, issue or event, through its evaluation/value judgment, in which it is expressed through an affective characteristic [13]) and beliefs (According to Fishbein et al., [13] beliefs represent information that a person has about an object, action or event that can therefore be linked to some attribute) about the characteristics of a specific product and the way it is manufactured, handled, or distributed can influence consumers' perceptions [14]. Consumer attitudes and beliefs about meat and meat products depend on the product itself and on the characteristics of the individual [12] and can be represented (see Figure 1) in three large groups of factors, namely: psychological, sensorial, and marketing (referring to placing the product on the market).

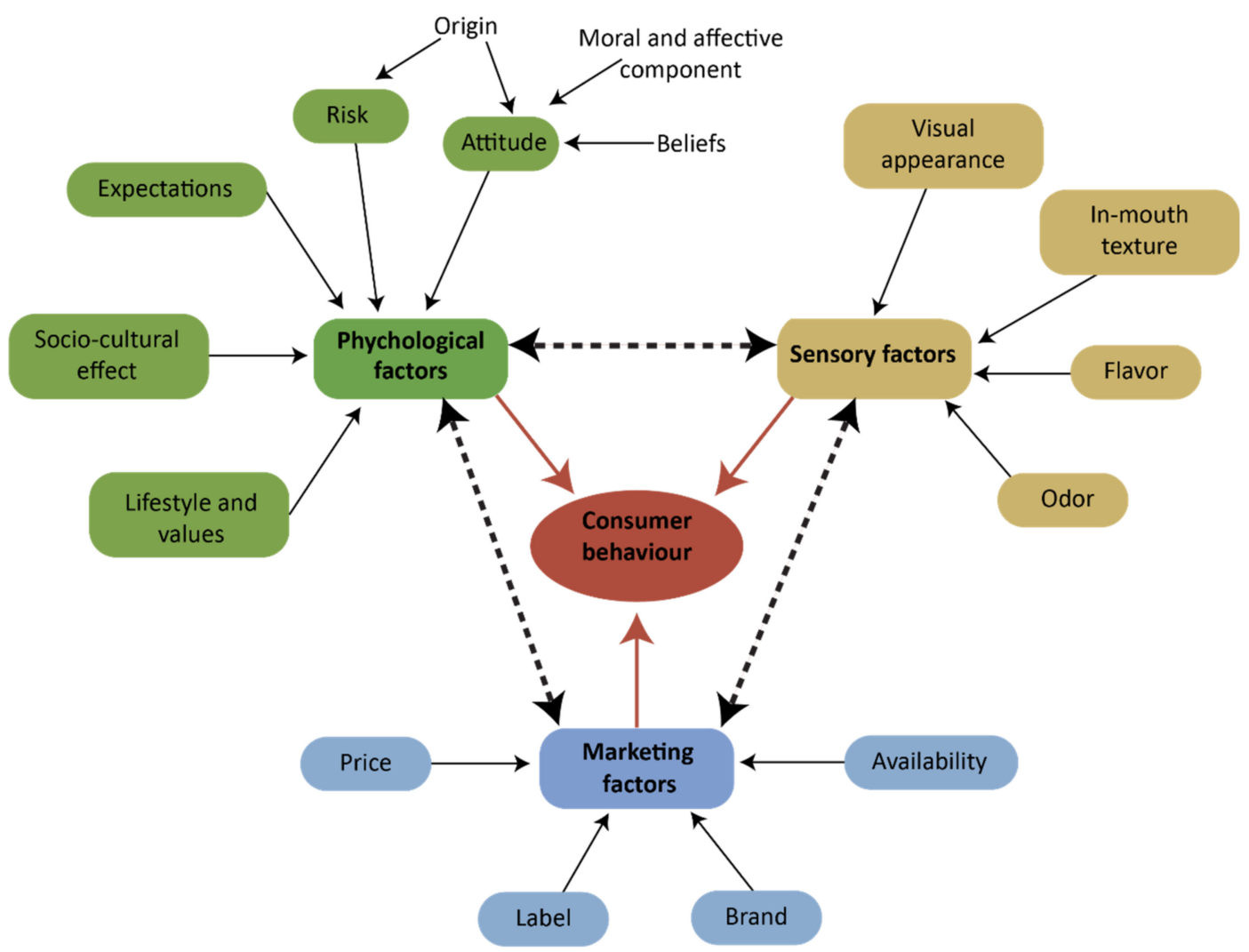

Figure 1. Multidisciplinary model of factors that affect consumer behaviour in food purchase/consumption decisions. Adapted with permission from Font-i-Furnols et al., [12]. @ Elsevier Ltd. 2014. 
In general, and regardless of its traditional character [15] and established social status, meat tends to have a negative image due to its association with the live animal, processing practices and slaughter conditions [16], the presence of blood [17], environmental issues [18] and religious, ideological, ethical or moral concerns [19].

Paradoxically, negative attitudes towards meat production seem to have a limited effect on purchasing behaviour, probably because of the minimal knowledge of the consumer that tends to rely on indirect information sources [20]. These negative attitudes towards meat are not necessarily linked with a reduction in meat consumption but tend to be related to changes in the role designated to meat within a meal (treated as an ingredient rather than as the most valued part of the meal) [12]. On the other hand, even though the public claims to be worried about matters such as animal welfare and strongly believes that it must be ensured and guaranteed, in some cases, this is not reflected in the purchase and consumption of meat [15]. This behaviour can be justified by the psychological effect of "suppress", which is directed towards the unpleasant and threatening memories consciously or unconsciously [21]. All this complex and time-consuming process is accelerated by attributes that consumers use to help them make these sorts of decisions., These attributes, in the case of food, and in particular meat, affect how consumers understand the quality of meat [20].

Consumers in all markets require pleasant, safe, healthy, and high-quality food products $[22,23]$. Nevertheless, the quality of the consumer's opinion is subjective and, therefore, assessments of meat quality may differ between individuals, societies, and cultures. However, the quality of the consumer's point of view is subjective and, therefore, evaluations of meat quality may vary among individuals, societies, and cultures [24], suggesting, for example, that quality represents characteristics or properties of a product that result in satisfying the physiological need of the consumer and/or their physiological needs. The argument about quality goes beyond the functional characteristics of the product, including the characteristics with an emotional character [25].

In the literature, there are three basic types of quality attributes: research, experience, and credibility. Research attributes, regularly referred to as "quality attributes", are normally used at the purchase location to assess the alternative choice [25] (see Figure 2).

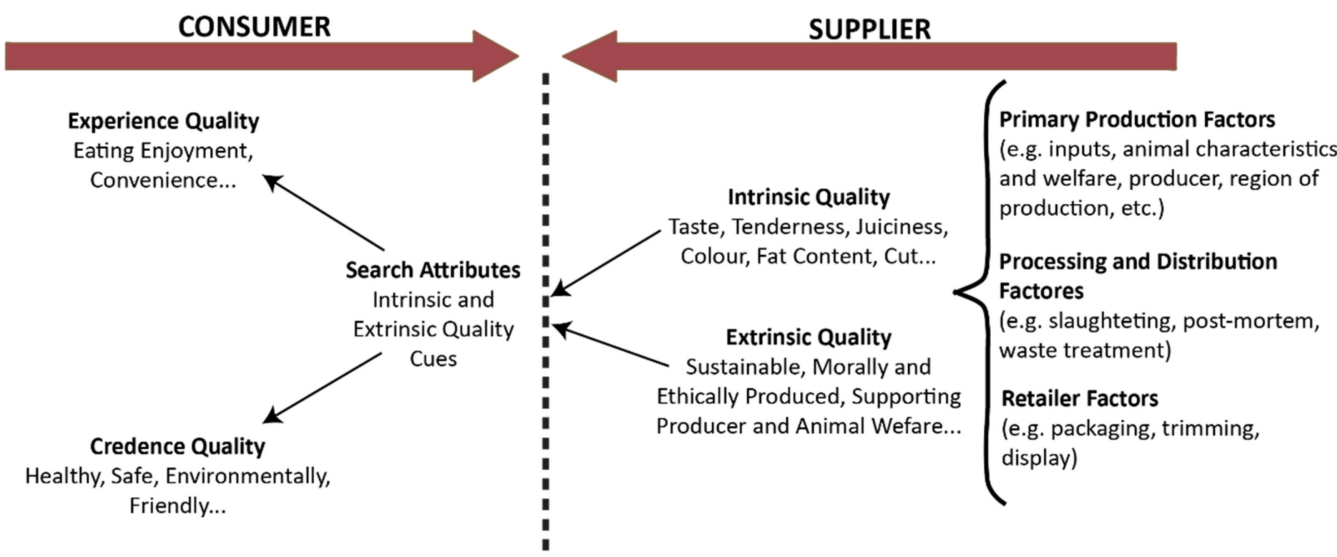

Figure 2. Attributes and interface between consumer and supplier. Adapted with permission from Henchion et al., [25]. (C) Elsevier Ltd. 2014.

These quality attributes can be divided into two types, intrinsic and extrinsic. Intrinsic attributes, described as visible inherent characteristics of the product, are significant in establishing quality expectations in many fresh food categories [25]. Perception of meat quality is normally associated with intrinsic meat attributes such as colour, visible fat content, and their cut [20]. These elements are only contradicted when the meat is acquired in a butcher's shop where it is believed to have better quality than when purchased in supermarkets and when the origin of the meat has an influence because it is believed that the "more homemade" production has better quality [20]. Place-of-purchase information 
represents a significant communication opportunity where relevant quality attributes can be used as leveraged to support positive quality assumptions [25]. Extrinsic attributes represent information related to the product itself, but that is not physically a part of the product [25]. These attributes, on which consumers assume meats' quality, are progressively more crucial, such as, for example, health, food safety, and consumption experiences.

Evidence suggests that at least two characteristics based on appearance are typically used by bovine meat consumers, where the cut type, colour, structure/type, and fat levels [20] have been perceived as influential in defining quality expectations. This subjective quality perception induces lower consumer confidence in the sector, increasing their uncertainty about quality expectations, which can lead to discontent. In fact, Grunert (2006) states that this dependence on intrinsic quality attributes may result from relatively extrinsic attributes available to support consumers' judgments. Extrinsic attributes usually mentioned for meat include dates, quality labels (including quality guarantee marks and symbols), place of purchase, packaging, price and information regarding the origin, animal fees, production, and processing. The origin and place of purchase have been referred to as the two most important extrinsic attributes for meat [20].

The autochthonous breeds in Portugal have a good biodiversity connection, as they have slower growth and are the result of specific territorial characteristics (orography conditions, climate, soil, land structure, and social and cultural traditions) [8]. Specifically, Jarmelista autochthonous breed is a beef production that respects biodiversity and has a sustainable production since it comes from highland pastures produced in traditional "Lameiros" (natural pastures found in altitude lands that grow without the interference of man), near waterways and natural moist areas and with herbaceous species adapted to the region's edaphic conditions, rye, and oat cereal pastures [8]. The Jarmelista farmers raise their animals without commercial feeds or other types of processed foods. This sustainable production method is, therefore, defined by raising the animals in free pastures with orography conditions and specific soil characteristics, which allow biodiversity preservation and implementation of animal welfare [26,27].

As such, the Jarmelista beef is the focus meat product of our research as it has characteristics that consumers can identify and value, as the literature indicates, and translate them into meat consumer preferences and behaviour. First, we aimed to evaluate the general trends in beef consumption in Portugal, with the goal to define consumer behaviour towards beef, and finally explore the existence of a specific group with similar concerns towards animal welfare, sustainability, and climate change. So, through a survey, we collected data regarding the consumer's preferences for beef from the autochthonous breed of the Jarmelo, which is characterised by a sustainable production method.

\section{Materials and Methods}

The developed methodology was based on an online survey (see Appendix A) that was launched nationwide, in 2021, to Portuguese potential beef consumers (adults, of both genders, with different incomes and education levels). Further, this survey was also performed face-to-face in some food sales stores. The survey was structured based on questions about intrinsic and extrinsic attributes found in theoretical research [28,29]. The scales used in the survey were validated with a Cronbach Alpha value that expresses a very high level of confidence and reliability of the collected data (Table 1).

Consumer perspectives were collected through a survey in Portugal. The questionnaire was subdivided into three main sections. The first section included questions related to bovine meat purchasing behaviour and consumption. This section examined the reason to consume meat, the meat consumption frequency (daily, three times a week, once a week, occasionally or others), as well as the habitual meat sale stores (producer, butcher, supermarket/grocery store, hypermarket, or others. The second section was related to the importance of meat choice purchasing attributes. Lastly, the third section included a question associated with socio-demographic characteristics, such as gender (female or male), age (from 18 to 31, from 32 to 49 and over 50), household (from 1 to 3 elements, from 
4 to 6 elements and over 7 elements) area of residence (urban and non-urban), occupation and nationality (Portuguese or other). Participation in the study was completely anonymous, voluntary, and confidential. A total of 491 completed surveys were obtained for further analysis.

Table 1. Cronbach Alpha values from the used scales in the survey.

\begin{tabular}{lccc}
\hline \multicolumn{1}{c}{ Scales } & Cronbach's Alpha & $\begin{array}{c}\text { Cronbach's Alpha } \\
\text { Based } \\
\text { on } \\
\text { Standardised Items }\end{array}$ & N of Items \\
\hline Meat quality attributes & 0.874 & 0.888 & 6 \\
\hline $\begin{array}{l}\text { Beef purchase } \\
\text { decision-factors to } \\
\begin{array}{l}\text { consider when making } \\
\text { the purchase }\end{array}\end{array}$ & 0.869 & 0.878 & 11 \\
\hline $\begin{array}{l}\text { Beef purchase } \\
\text { decision-concerns } \\
\text { before purchase }\end{array}$ & 0.910 & 0.910 & 7 \\
\hline $\begin{array}{l}\text { Reasons for the } \\
\text { beef consumption }\end{array}$ & 0.887 & 0.902 & 13 \\
\hline
\end{tabular}

The participants were divided into two focal groups according to their residence area (non-urban: group 1; urban: group 2).

All the reported statistical analyses were conducted using SPSS (IBM SPSS Statistics 28). The descriptive analysis allowed data summary measures in all the elements of the sample. In this way, it was possible to characterise the behaviour of the variables. Since the survey scales were validated, we could observe any correlation between the demographic characteristics of the sample and the environmental concerns expressed on meat consumption, using correlation tables. Factor analysis was performed to identify which underlying factors are measured by a much longer number of observed variables. The factor analysis was performed by principal component analysis (PCA). The number of components was chosen by the tangent method of the scree plot, and the suitability of the data to perform the factor analysis was studied by the Kaiser-Meyer-Olkin (KMO) test and Bartlett's test of sphericity. The PCA loading matrix was rotated using a varimax rotation with Kaiser normalisation. In the end, each component was defined as a descriptor or the inquire.

Finally, a cluster analysis was made to assess if it was possible to identify a group of consumers with different behaviours. The Ward method was firstly used to define the number of clusters, and then the K-mean cluster method was used to define the clusters. The statistical significance was assessed by an ANOVA analysis.

The analysis of clusters tries to seek a group of initial data into groups or categories by using the observed values in the variables, knowing neither the number of groups nor the members of the group. This analysis groups a set of cases into homogenous groups so that the individuals belonging to a group are as similar as possible to each other and different from the others [30]. This analysis will allow us to determine if there is a specific group of consumers that link their environmental concerns with meat consumption and other groups of consumers who do not do it.

\section{Results}

Socio-demographic characteristics of the sample population involved in this study are summarised in Table 2. The surveys were launched in urban and non-urban areas of the country. Most of the respondents, from the 491 validated answers, were female (59.1\%), aged between 18 and 31 years old (54\%), with a household composed of one to three elements (58.9\%), and lived in urban areas (70.5\%). Additionally, in Figure 3, we can 
observe that $89.4 \%$ of the inquired consumed beef, and they do so because it is "Nice", "Usual", "Natural" and "Necessary". These results are in accordance with data previously reported by Piazza and colleagues. In this work, the research evaluated the $4 \mathrm{~N}^{\prime} \mathrm{s}$ (Normal, Necessary, Natural, Nice) theory. This is the justification that consumers commonly use to defend their choice of eating meat [31]. The other 10.6\% said that they dot eat meat because "It is not nice", "It is not necessary", and "It is not sustainable".

Table 2. Summary statistics for demographic variables.

\begin{tabular}{ccc}
\hline & Frequency & Percentage (\%) \\
\hline \multicolumn{1}{l}{ Total sample size } & 491 & 100 \\
Gender & & \\
Female & 290 & 59.1 \\
Male & 197 & 40.1 \\
Did not answer & 4 & 0.8 \\
Age (years) & 265 & 54 \\
$18-31$ & 155 & 31.6 \\
$32-49$ & 67 & 13.6 \\
$\geq 50$ & 4 & 0.8 \\
Did not answer & 289 & 58.9 \\
Type of household & 181 & 36.9 \\
1-3 elements & 6 & 1.2 \\
4-6 elements & 14 & 2.9 \\
7 or more elements & 1 & 0.2 \\
Did not answer & & \\
Omitted & 346 & 70.5 \\
Area of residence & 139 & 28.3 \\
Urban & 6 & 1.2 \\
Non-urban & &
\end{tabular}

a

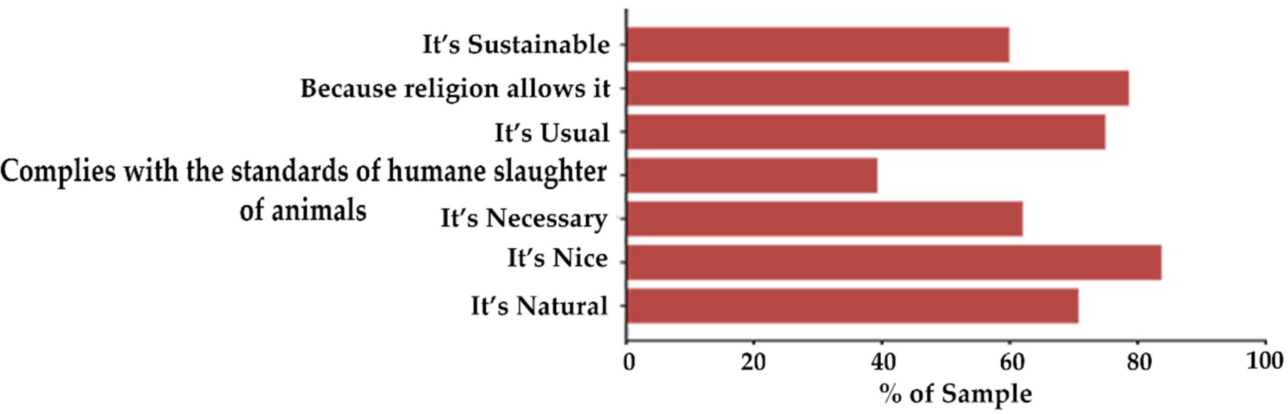

b

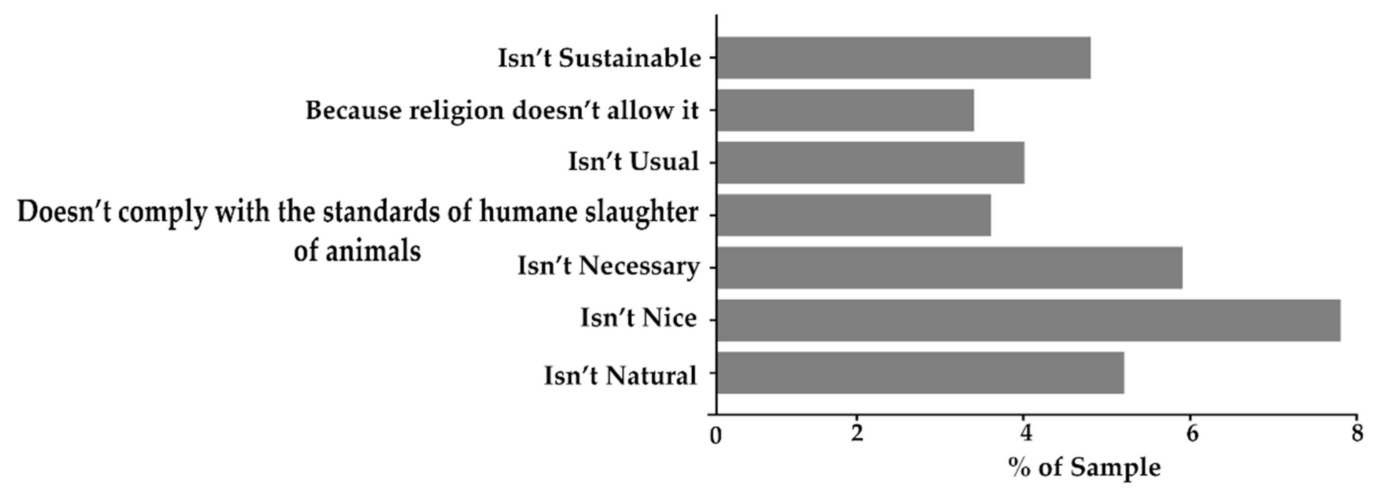

Figure 3. (a) Reasons why consumers eat beef. (b) Reasons why consumers do not eat beef.

From the answers obtained in the questionnaire, most of the respondents consume meat three times a week $(32.4 \%)$ and purchase meat at the butcher $(29.7 \%)$ or the butcher 
and hypermarket $(11.4 \%)$. No significant associations were found $(p>0.05)$ between the frequency of meat consumption and the socio-demographic variables (age, sex, origin, and education level). Concerning bovine meat attributes as an influence for purchase, all of them were considered as "very important". However, consumers pay more attention to attributes such as "freshness", "taste/flavour", "tenderness", and "juiciness" (Figure 4). Further, the origin of the meat product was the less important attribute to the consumers' purchase decision. Conversely, there are some studies where the origin of meat is considered the most important quality cue $[32,33]$. In a study carried out by Merino and collaborators, the authors studied the differences regarding meat consumption between households with and without children. Both households considered attributes such as country of origin and colour as the least important. In the case of the most important attributes, there was a difference, as households without children consider taste/flavour the most important cue while households with children consider it as having organic labelling [34].

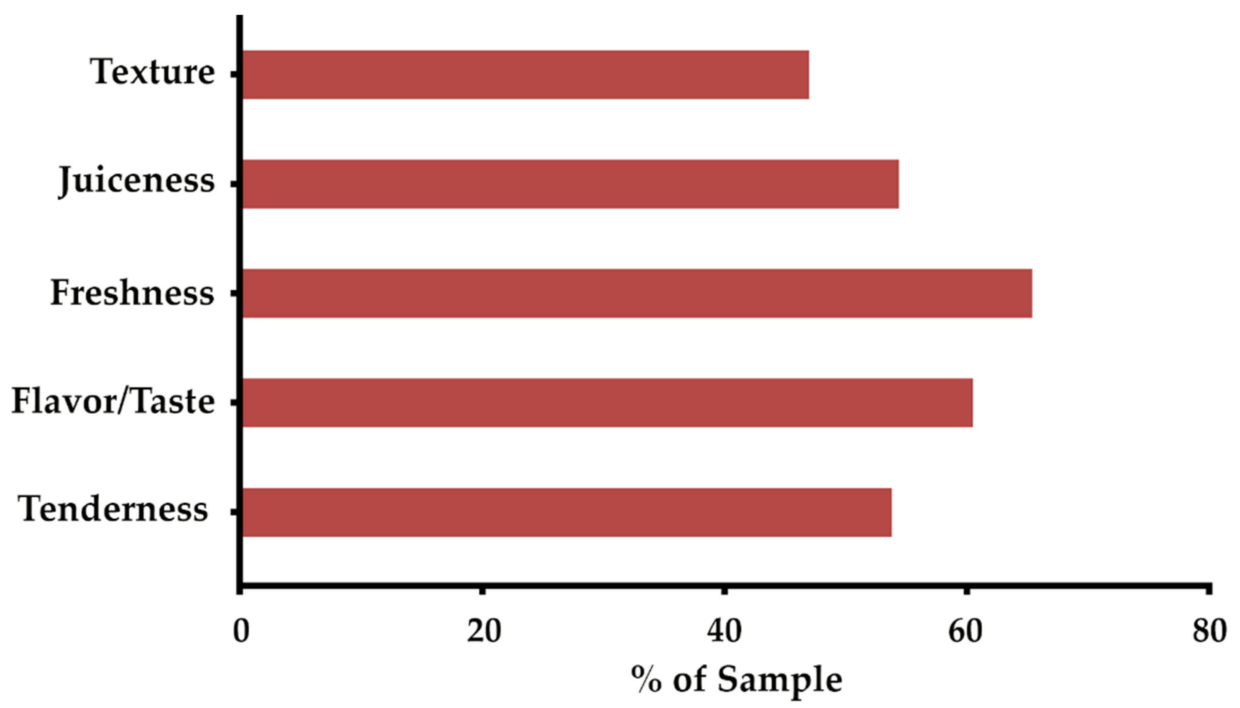

Figure 4. Consumer's quality attributes preferences.

Regarding the purchase decision making, it was observed that the inquired take into consideration the factors mentioned in the survey; however, the factors that have a higher impact on the purchase decision are appearance (58.5\%), expiration date $(58.7 \%)$, packaging date $(51.9 \%)$, and prefer quality over quantity (51.5\%) (Figure 5). This analysis is particularly interesting when correlating these results with the results regarding the place of the purchase; as stated above, the respondents tend to make their meat purchase at the butcher, where there is no shelf-life or packaging date directly associated with the product. On the other hand, when the chosen place to purchase is the hypermarket, the attribute that has a higher impact in assessing the quality of the product is their appearance. The colour, quantity of visible fat, and the ratio of quality-price are the factors consumers consider when making their purchase, as was also registered by [35]. According to Webb et al., in some countries, such as the USA, the fat content has a positive effect on the juiciness and tenderness of the meat [36]. On the other hand, the amount of fat is normally perceived as an unhealthier product [35]. However, in Europe, 3-4\% of fat content is normally considered as sufficient taste and juiciness to the meat [37]. Further, Eldesouky and colleagues reported that consumers are more prone to choose a meat product with a lower price than an eco-friendly product with a higher price [38]. 


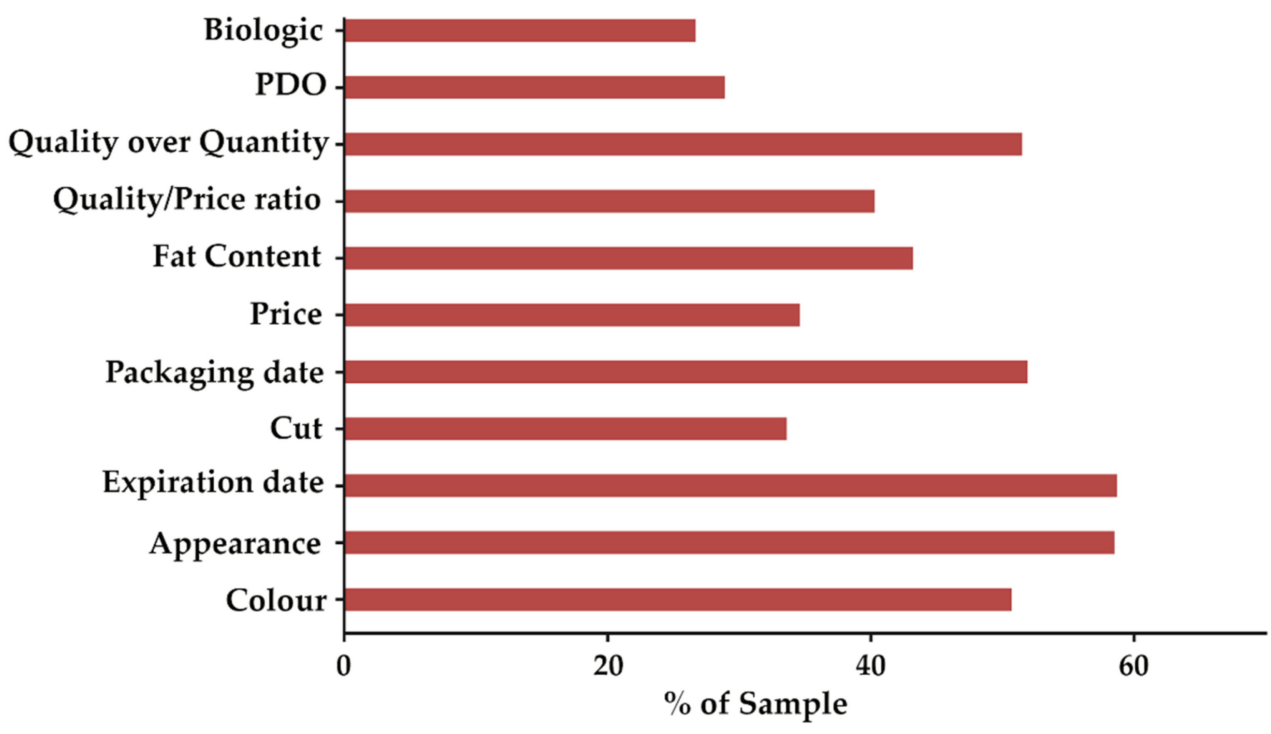

Figure 5. Factors that consumers consider as "very important" when making the purchase.

Relatively to the concerns about the way cattle are produced, their welfare, the transport conditions, or the slaughter method, it was observed that the inquired consumers never thought about these factors (Figure 6). However, the pre-slaughter conditions have a crucial impact not only on animal welfare but also on the quality of the final product [39]. On the other hand, factors such as the guarantee of compliance regarding hygiene and safety conditions of the production method, slaughter, and commercialisation were considered "very important". Moreover, it should be noted that, in general, the type of concerns listed in the questionnaire are not considered by many of the respondents before deciding to purchase or consume beef.

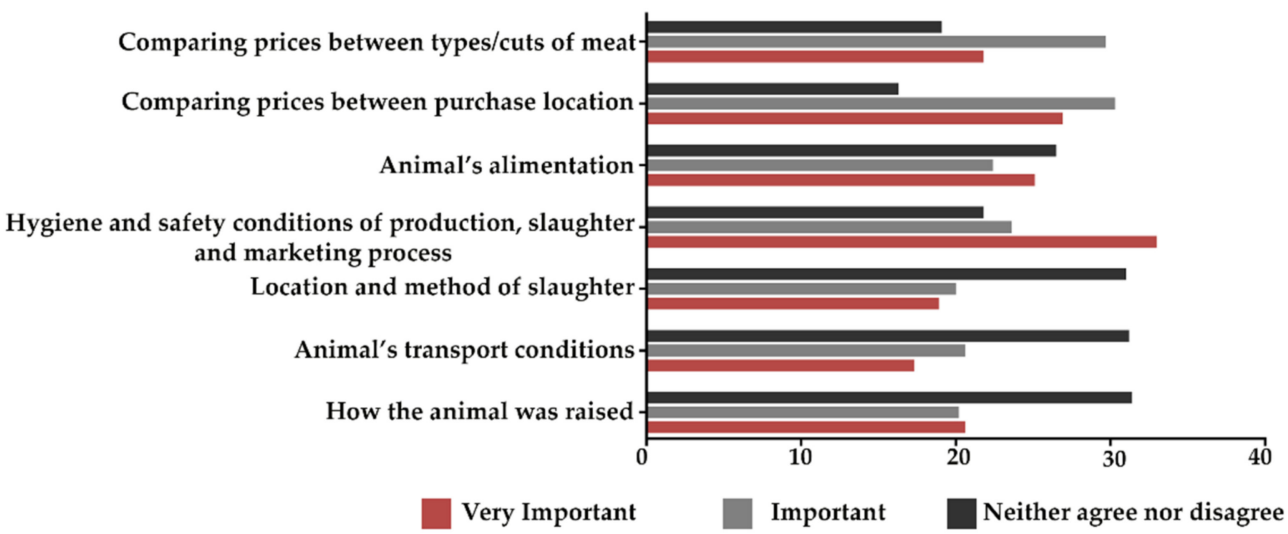

Figure 6. Consumers' opinion regarding the way cattle are produced, their welfare, the transport conditions, or the slaughter method.

In Figure 7, we can observe the consumers' opinions regarding the environmental concerns with the consumption of meat. It was observed from the answers that $56.2 \%$ of the inquired agrees ("totally agrees" and "agrees") that the consumption of meat has a negative impact on the environment, such as contributing to climate changes and pollution [40]; however, just $30.1 \%$ of the respondents are willing to reduce the consumption of meat due to environmental reasons, and $40 \%$ agree that eating less meat is better for the environment. In a study carried out by Figueiredo et al., the authors assessed the awareness and willingness of university students to reduce meat consumption. A total of $75 \%$ of the inquired students, mainly female students, demonstrated a willingness to reduce their meat consumption owing to environmental reasons [2]. Studies show that altering 
dieting habits by decreasing meat intake and eating more plant-based foods is essential for the environment [41]. However, the lack of knowledge of consumers of the negative impact of meat consumption on the environment is the biggest impediment towards a more climate-friendly consumer behaviour [42]. Further, the impact of meat consumption on the environment is underestimated [43], and there's a lot of scepticism around the scientific evidence that associates meat consumption with climate change [44-46].

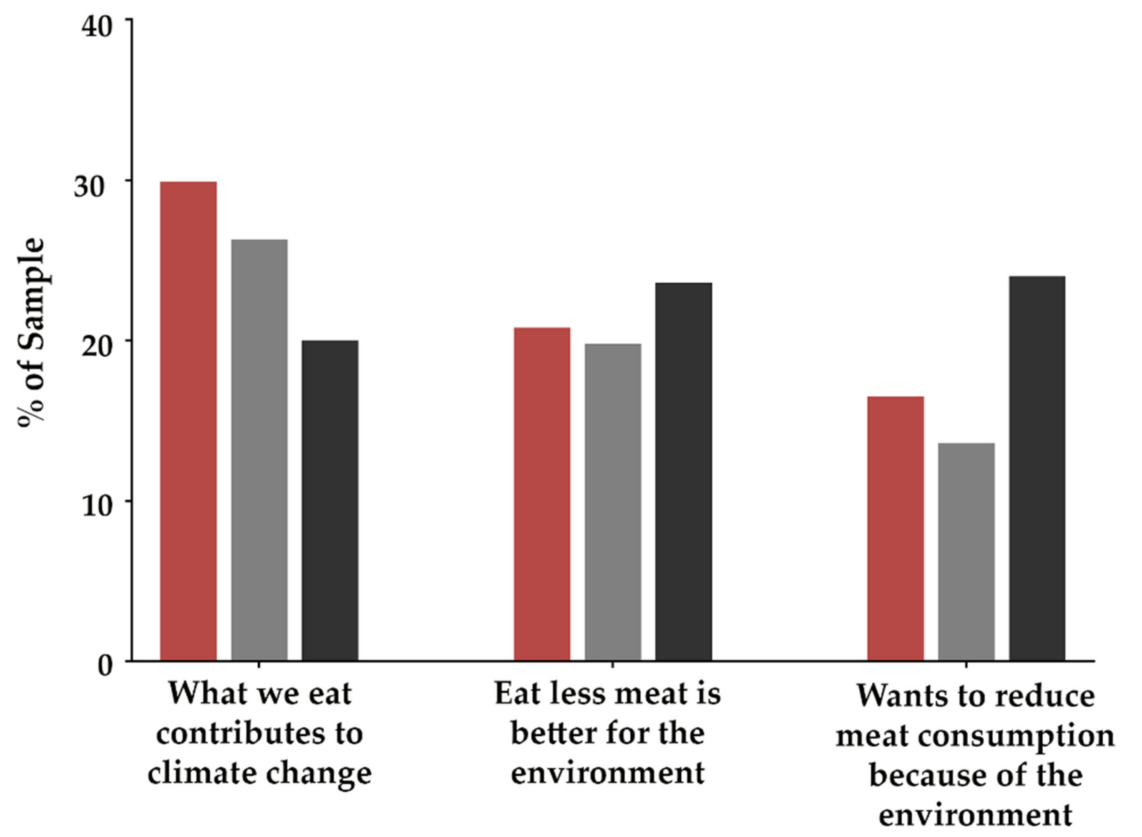

Very Important

Important

Neither agree nor disagree

Figure 7. Consumers environmental concerns regarding meat consumption.

Correlating the environmental concerns with the purchase and consumption of meat (Figures 8 and 9), we observed that they are more evident among the urban respondents and have a higher incidence in the younger age group. As for animal welfare, there are no differences between the urban and non-urban groups. The two groups had a different opinion in the following concerns: reasons and behaviour of beef consumption, their evaluation of the quality of the meat, and whether their behaviour fit the behavioural trends reported in the literature: health, sustainability, and transparency of the method of animal production and respect of animal welfare.

The variation is visible for the age of the inquired, and respondents with ages ranging from 23 to 49 years have a greater concern with animal welfare. Animal welfare attitudes have been associated with socio-demographic factors, such as gender, age, and level of education [47]. In this study, there were no differences between genders, contrary to results obtained for other authors [48-50]. For example, in a study carried out by Blanc and collaborators, the role of gender in assessing consumer consciousness towards animal welfare was evaluated. From the 512 respondents, the authors could conclude that women seem to be more sensible in relation to animal well-being [51]. However, there's a difference between acknowledging the importance of animal welfare and making the purchase based on that information due to the fact that an "animal-friendly" product is associated with an increase in the price [52]. 

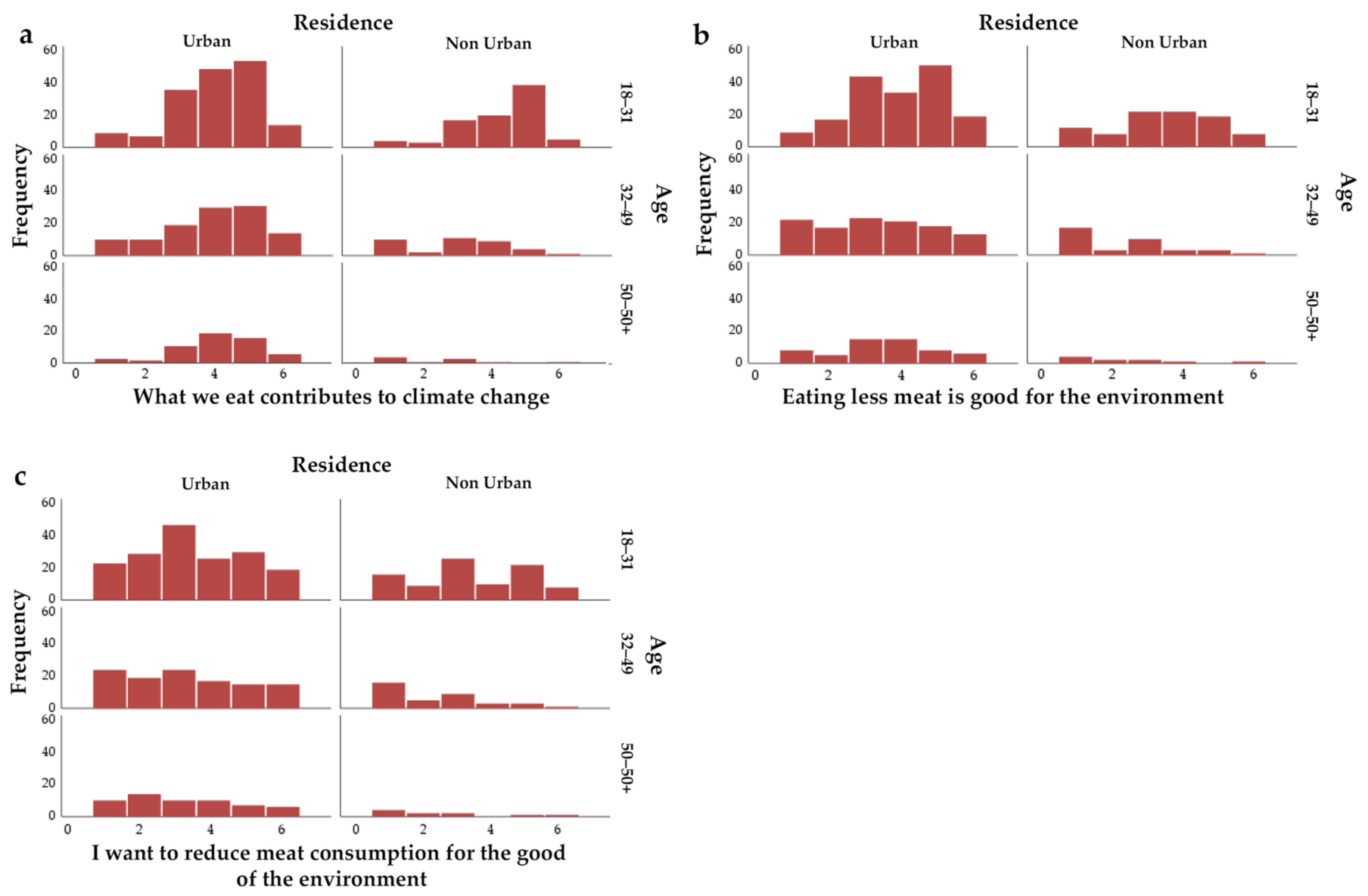

Figure 8. Histograms relating to the environmental concerns in eating beef meat such as, (a) the contribution to climate change, (b) the quantity of meat consumed and its impact (c) wiliness to reduce meat consumption, with the age and type of residence of the people: 1-Nothing important; 2-Not important; 3-Never thought; 4-Important; 5-Very important; 6-No answer.

From the descriptive results presented, a principal component analysis (PCA) was carried out to identify groups with highly correlated variables that were not immediately noticeable. This analysis allows a better understanding of the obtained data and, at the same time, reduces the number of variables to be analysed [53]. The results obtained had a KMO (Kaiser-Meyer-Olkin) consistency of 0.969. Four components were chosen in the PCA analysis with an accumulated explained variance of $71.0 \%$. From the PCA analysis, four descriptors were identified:

- Factorial component 1-Why you consume beef

- Factorial component 2-Beef attributes

- Factorial component 3-Concerns to have when purchasing beef

- Factorial component 4-Environmental concerns about beef

With the PCA analysis, we can understand that the reasons why beef is consumed can be grouped in one single descriptor. The beef attributes, except for the origin and perception of the quality / price relation, are also very well explained by the model. From the individual analyses, we realised that they were all marked as "very important" for decision-making. In the last two components, there are some items that appear in more than one descriptor. There are issues that group together as concerns with beef, but which also play an important role in explaining component 4-environmental concerns (issues related to price and its evaluation) and even as attributes of beef to take into consideration for the purchase decision, component 2 found (questions that take into account the origin of the product, 
whether it is organic, whether it has protected designation of origin (PDO), what is its price-quality ratio).
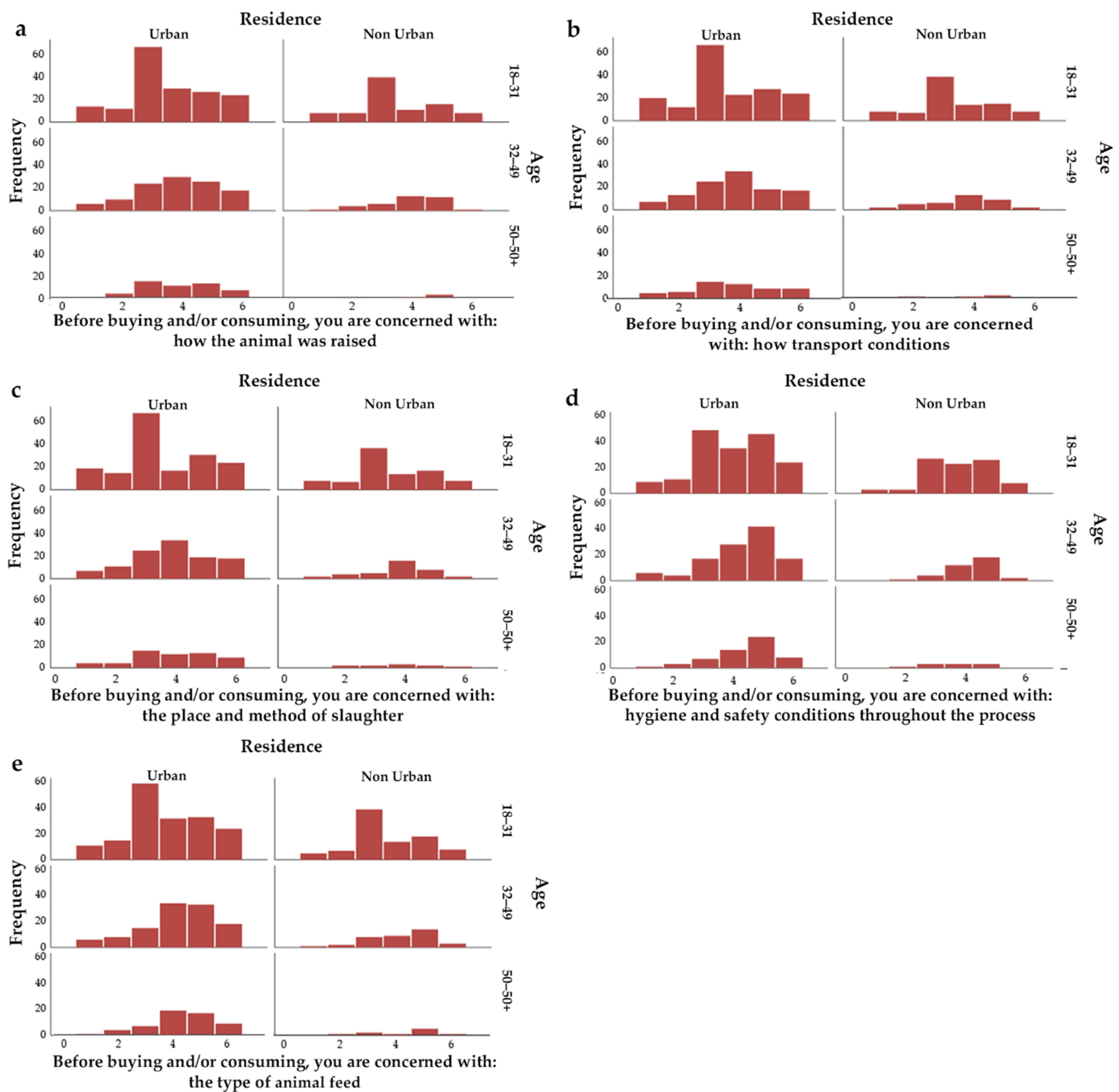

Figure 9. Histograms of the purchase concerns according to at (a) how the animal was raised, (b) transport conditions, (c) the place and method of slaughter, (d) the hygiene and safety conditions throughout the process, (e) the type of animal feed relating to the age and type of residence of the people: 1-Nothing important; 2-Not important; 3-Never thought; 4-Important; 5-Very important; 6-No answer.

Based on these factors, an attempt was made to find groups of consumers who could differentiate themselves and thus constitute differentiated market targets to be worked on according to their specificities. 
So, to group the consumers, we firstly use the Ward method to identify the number of possible clusters, and through the K Means method, three groups of valid answers with statistical relevance were defined, as can be seen in Table 3, from the obtained ANOVA analysis.

Table 3. ANOVA analysis.

\begin{tabular}{lcccccc}
\hline & \multicolumn{2}{c}{ Cluster } & & Error & \multicolumn{2}{c}{ Percentage (\%) } \\
\hline & Mean Square & df & Mean Square & df & Z & Significance \\
\hline Beef & 66.332 & 2 & 0.650 & 470 & 102.061 & $<0.001$ \\
$\begin{array}{l}\text { Consumption } \\
\text { Beef Attributes }\end{array}$ & 13.644 & 2 & 0.351 & 470 & 375.487 & $<0.001$ \\
$\begin{array}{l}\text { Purchase } \\
\text { decision }\end{array}$ & 7.198 & 2 & 0.989 & 470 & 7.281 & $<0.001$ \\
$\begin{array}{l}\text { Environmental } \\
\text { concerns }\end{array}$ & 66.739 & 2 & 0.738 & 470 & 89.085 & $<0.001$
\end{tabular}

Note: F-tests should only be used for descriptive purposes because clusters were chosen to maximise differences between cases in different clusters. The observed significance levels are not corrected for this and, therefore, cannot be interpreted as tests of the hypothesis that the cluster means are equal.

From that, we performed an analysis of clusters however this analysis did not allow us to identify the composition of the groups of consumers. From the Figure 10, we can observe that there are elements that overlap in the different clusters, this way it is not possible for us to identify the elements that can be differentiated in any given cluster.

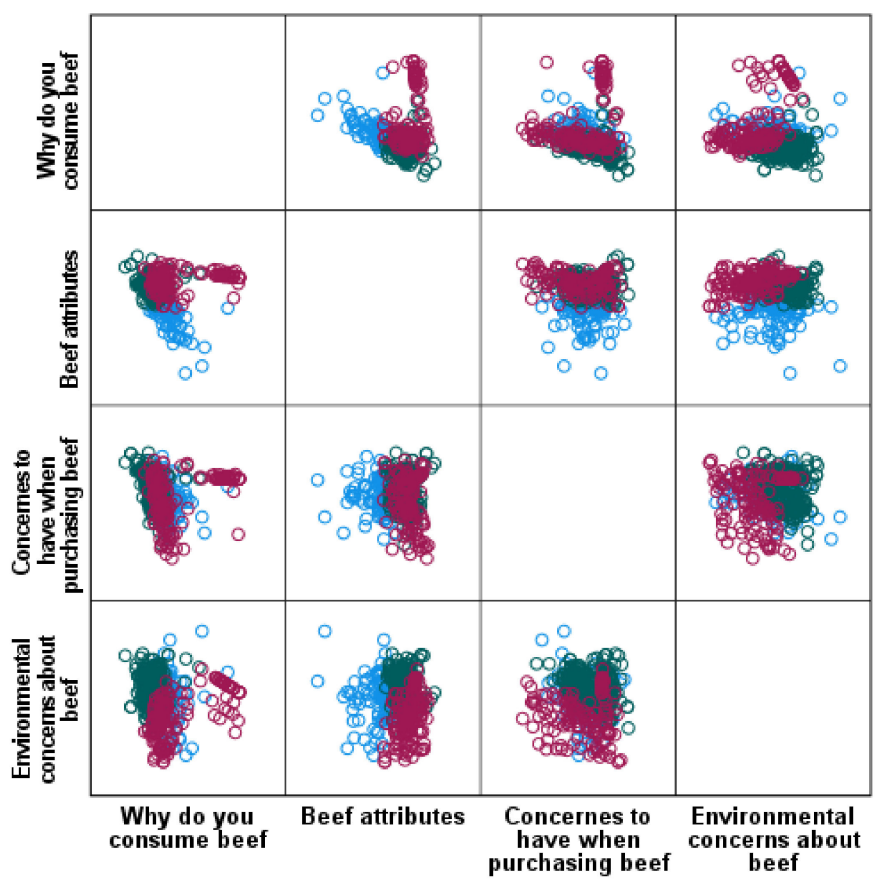

Cluster

$\bigcirc 2$

$\mathrm{O}_{3}$

Figure 10. Scatter plots of the descriptors defined by the PCA coloured by the cluster number.

From the collected data, we can state that is a paradox between the concerns stated by the respondents and their effective behaviour. This paradox was already identified in other studies about the behaviour of the green consumer in Portugal [54]. In the food sector, there has been a greater seek for organic food in Portugal [55]. However, meat consumption still does not reflect this requirement, probably because the consumer who seeks organic food does not have access to them or is unaware of the existence of this product [56,57]. Furthermore, due to the results obtained, meat consumers do not take into consideration their pleasure from eating meat above the issues regarding the environment and animal 
welfare. The demand for emotional satisfaction derived from food is strong and allied to a lack of knowledge or access to the supply of organic beef, and it may lead to inertia and maintenance of consumption behaviours.

Considering the results of the analysis carried out, it was also possible to identify the determinants of beef quality and the attributes to identifying this quality. In other words, we were able to understand how consumers make their decision to purchase and consume beef, identifying the intrinsic and extrinsic attributes that base the consumer's purchase decision.

\section{Discussion}

Our study focuses on the autochthonous breed of Jarmelo beef, which, being of sustainable production, is less attractive as a means of production owing to its low economic profitability due to the lower yield of the breed. This situation has been identified as a key obstacle in the production phase since the volumes produced are too small, even at a regional level, and due to the low profitability, few producers are committed to raising animals of this breed and/or intending to increase their number [8]. Whoever produces it does not value the qualities of organic production of the animal and does not distinguish the value of this type of meat.

The characterisation of the Jarmelista meat value chain was carried out through observation and interviews with ACRIGUARDA, as well as through surveys of its players to understand how the links were established between breeders, slaughtering, distribution, commercialisation companies, and how the increased value to the final product was processed throughout the entire chain. It was also possible, through the surveys, to perceive what they considered important in the value of their offer to final consumers.

From the collected information, it was possible to understand that the Jarmelista meat value chain is quite short (see Figure 11). Not only because there are few producers, but there are also few suppliers that sell the product directly to the final consumer or through restaurants that have Jarmelista meat on their menu.

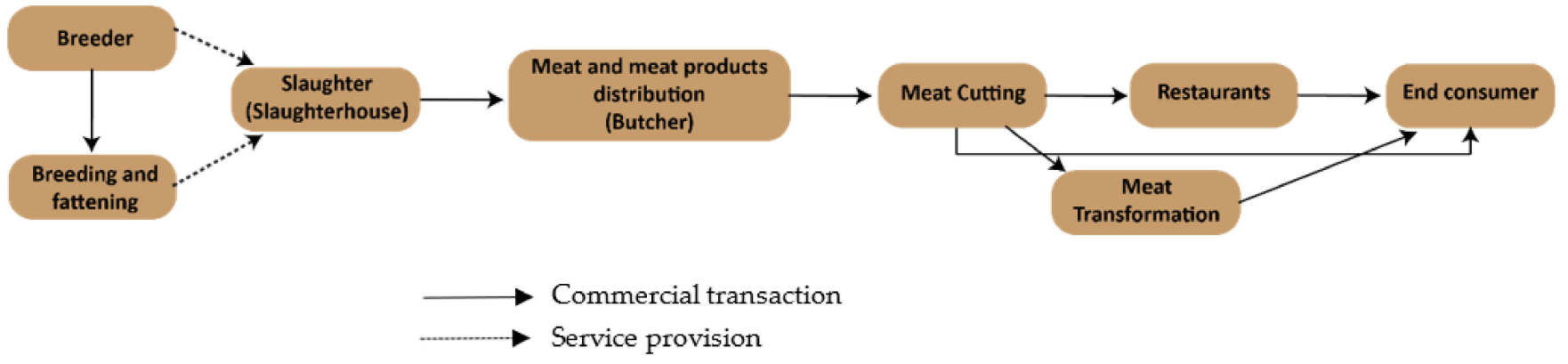

Figure 11. Beef value chain.

Having already characterised the producers and their explorations, we seek to understand their opinion on how the final consumers evaluate the Jarmelista meat that they acquire and how they make the purchase decision. So, the Jarmelista breed producers were inquired. From these, we received 19 valid answers, which corresponds to $95 \%$ of identified producers. The obtained results demonstrate that the producers still value all the attributes, considering that the final consumer seeks Jarmelista beef by the taste/flavour $(84,2 \%$ consider "very important"), freshness $(63,2 \%$ consider "very important"), juiciness $(63,2 \%$ consider "very important") and texture $(63,2 \%$ consider "very important") [8]. For the making of the purchase decision, producers consider that the most important factors are the visible fat on the meat, the appearance, cut and expiration, and packaging date. The purchasing decision influencing factors identified are factors that have nothing to do with beef production and the responsibility of suppliers and slaughter conditions, transport of animal carcasses, and hygiene and safety throughout the slaughter and marketing process. 
All suppliers acquire to the individual producers and do so, in majority twice a week, in the carcass. Transport, most of the time, is on account of the company that purchases the meat, and the sale is performed without packaging. These intermediaries claim that they buy Jarmelista meat because the consumer values it and because they consider it important for their business. Further, they consider that the consumer acquires Jarmelista meat due to its organoleptic characteristics, price or price-quality ratio, cut, and appearance. On the other hand, they believe that the consumer gives less importance to expiration and packaging date because it is based on the trust established between the final consumer and the butcher, and in this case, the product does not include packaging. The biological characteristics and the possibility of being PDO are not considered relevant by some of the suppliers. These intermediaries, even though they are concerned about sustainability issues, they do not consider it important to share this type of information.

Applying the model represented in Figure 2, which served as support for the construction of our analysis and reflection, we observed that the organoleptic characteristics of Jarmelista meat and their hygienic-sanitary conditions are determinants for the purchase and consumption of meat. These factors hardly differentiate Jarmelista beef from other beef breeds.

Sustainability is still not reflected in the purchase decision of consumers, and it is the main difference of the Jarmelista breed compared to others and the cause of having differentiating attributes appreciated and pursued after by end consumers, such as tenderness and juiciness $[3,58,59]$. Somehow, the sustainable production of the breed must be reflected in the production value chain so that consumers can identify and value it as well [60]. So, if we tried to relate the importance that biologic production may have in shifting consumer behaviour, we would have a productive framework in which valuable activities would focus on sustainable animal production, respect for animal welfare during its growth and transport, and under conditions of reduction of its carbon footprint, that not only come from its production method but also from its territorial marketing and through a specific channel, which implies less transport and packaging waste $[60,61]$.

Producers play a fundamental role in the development of activities that add value to Jarmelista meat. In concerted action with suppliers, they must make a difference in terms of communicating the characteristics of the meat so that they can respond in a distinguished way to the emotional needs of consumers' meat consumption. Offering this value, consumers will fulfil the search for pleasure, habit, and naturalness related to the consumption of beef and will also be able to have the satisfaction of consuming meat from a sustainable production, being rewarded with the contribution to the environment and respect for the well-being animal. Furthermore, our findings regarding the consumer's behaviour seem to be in line with the results obtained, in a recent study, by Budhathoki and colleagues, where Nepalese consumers also demonstrated greater concerns towards environmental concerns. In this study, the authors also acknowledged that the socioeconomic background also influenced the preferences and behaviour of the consumers [62]. From our results, it is also relevant to point out that Portuguese consumers also gave importance to the origin of the meat, considering the positive aspects of regional production and its impacts on the environment [63].

Nevertheless, our study presents some limitations when it comes to the dimension of the sample and the method of recruiting the participants, which may lead to a bias towards a restrictive age gap. Notwithstanding, the preferential method of recruiting was online, given the fact that during the time of data collection, there was a diverse range of mobility restrictions due to the global pandemic.

\section{Conclusions}

Nowadays, consumers show greater sensitivity to the impact of meat consumption on the environment and animal welfare. With the estimated increase in meat consumption, due to the increase in the population, animal production also increases, so it is important to adopt more strategies to reduce its impact on the environment. Animal production is 
responsible for a large part of climate change as well as the carbon footprint. Therefore, it is urgent to opt for a more sustainable way of producing breeds, such as the Jarmelista breed (Portuguese autochthonous breed). Beef from autochthonous breeds is normally considered to have high quality due to their juiciness and taste and comply with the sustainable production criteria.

Although in Portugal, it seems that meat consumers are not yet translating their environmental concerns to their meat preferences and behaviour, it is a consumer trend that, in time, will have a greater impact in the country and in meat production, as it is observed in other European countries. Despite our study limitations, it seems to express a typical Portuguese meat consumer behaviour and preferences. The results have a significant managerial impact since the farmers may understand that to follow consumer trends, they must differentiate their meat product and begin to assemble marketing strategies that show to the consumers the benefits of consuming this type of product, and that explains the increase in the market value. Furthermore, it is important to create solid communication with all the intervenients in the process (producers and suppliers), to be more competitive in the market.

So, local farms must have the support of local government institutions not only for financial help but also because of the impact of the production of these autochthonous breeds on the region.

Author Contributions: Conceptualization, T.P. and P.C.; methodology, T.P. and M.C.S.; software, T.P. and M.C.S.; validation, T.P., P.C. and M.C.S.; formal analysis, T.P. and T.A.J.; investigation, T.P. and P.C.; writing—original draft preparation, T.P. and T.A.J.; writing—review and editing, T.P., T.A.J., M.C.S. and P.C.; project administration, T.P. and P.C.; funding acquisition, T.P. and P.C. All authors have read and agreed to the published version of the manuscript.

Funding: This work received financial support from PT national funds, namely: PDR2020, Project Valor Jarmelista-valorização territorial pela preservação da identidade e genética da raça Jarmelista (Jarmelista territorial recovery value for the preservation of the identity and the genetic of Jarmelo indigenous race of ruminants). PDR2020-101-030749; (FCT/MCTES, Fundação para a Ciência e Tecnologia and Ministério da Ciência, Tecnologia e Ensino Superior) through the project UIDB/50006/2020 | UIDP/50006/2020. Mafalda Sarraguça thanks FCT (Fundação para a Ciência e Tecnologia) for funding through program DL 57/2016-Norma transitória.

Institutional Review Board Statement: Not applicable for studies not involving humans or animals.

Informed Consent Statement: Informed consent was obtained from all subjects involved in the study.

Data Availability Statement: The data presented in this study are available on request from the corresponding author. The data are not publicly available due to respect of privacy rules.

Conflicts of Interest: The authors declare no conflict of interest and the funders had no role in the design of the study; in the collection, analyses, or interpretation of data; in the writing of the manuscript, or in the decision to publish the results.

\section{Appendix A Perceptions and Trends on Beef Consumption}

\section{Do you consume beef?}

Yes

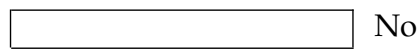

2. If you answer "yes", please go to answer set (2a) and continue taking the survey. If you answer "no", please go to answer set $(2 \mathrm{~b})$ and go to respondent characterisation (end of survey).

(2a) Why do you eat beef:

- It is natural (it is a biological and natural issue of the human condition)

Yes

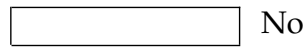


- It is necessary

(for survival, strength, development and health)

Yes

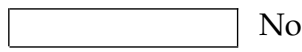

Do not know

- It is normal, usual

(Historical human behaviour and in accordance with social norms)

Yes No

Do not know

- It is good

(taste good, have pleasure)

Yes

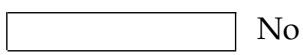

No

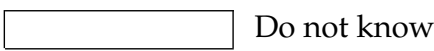

- Complies with the norms for "human" animal slaughter

Yes No

Do not know

- My religion allows it

Yes
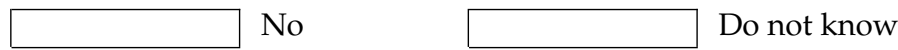

- Meat is sustainable

Yes

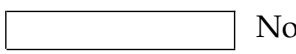

No

Do not know

\section{(2b) Why do you not eat beef:}

- It is not natural

(it is a biological and natural issue of the human condition)

Yes No

Do not know

- It is not necessary

(for survival, strength, development and health)

Yes

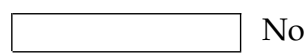

No

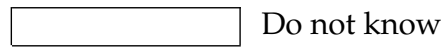

- It is not normal

(Historical human behaviour and in accordance with social norms)

Yes No

Do not know

- It is not good

(taste good, have pleasure)

Yes No

Do not know

- Does not meet the norms for "human" slaughter of animals

Yes No

Do not know

- My religion does not allow it 
- Meat is not sustainable

Yes No

Do not know

\section{What is the frequency of meat consumption?}

Daily

Three times a week

Once a week

Occasionally

Others

\section{Where to buy beef (check all possible options)}

To the producer

At the butchery

At the supermarket or grocery store

At the hypermarket

Others

5. Point out the importance you attach to the following characteristics of beef: (1Not that important; 2-not important; 3-never thought about it; 4-important; 5very important)

\section{a. What quality attributes are you looking for in the beef you consume?}

Tenderness

Flavour/Taste

Freshness

Juiciness

Texture

Origin

\begin{tabular}{|l|l|l|l|l|}
\hline 1 & 2 & 3 & 4 & 5 \\
\hline 1 & 2 & 3 & 4 & 5 \\
\hline 1 & 2 & 3 & 4 & 5 \\
\hline 1 & 2 & 3 & 4 & 5 \\
\hline 1 & 2 & 3 & 4 & 5 \\
\hline 1 & 2 & 3 & 4 & 5 \\
\hline
\end{tabular}

b. How do you decide you beef purchase?

Pay attention

to Colour

Pay attention to the Cut

Pay attention to the Appearance

Pay attention to the Visible Fat Content Pay attention to the Expiration Date Pay attention to the Packaging Date Pay attention to the Price

Pay attention to the Ratio Quality/Price Less quantity and more quality

Pay attention to the if has the PDO labelling Pay attention to the if is Biologic

\begin{tabular}{|c|c|c|c|c|}
\hline 1 & 2 & 3 & 4 & 5 \\
\hline 1 & 2 & 3 & 4 & 5 \\
\hline 1 & 2 & 3 & 4 & 5 \\
\hline 1 & 2 & 3 & 4 & 5 \\
\hline 1 & 2 & 3 & 4 & 5 \\
\hline 1 & 2 & 3 & 4 & 5 \\
\hline 1 & 2 & 3 & 4 & 5 \\
\hline 1 & 2 & 3 & 4 & 5 \\
\hline 1 & 2 & 3 & 4 & 5 \\
\hline 1 & 2 & 3 & 4 & 5 \\
\hline 1 & & 3 & & \\
\hline
\end{tabular}




\section{Before buying and/or consuming, you are concerned with:}

How the animal was raised The animal's transport conditions The place and method of slaughtering the animal The hygiene and safety conditions of the production, slaughter and marketing process The type of animal feed Compare prices between places of purchase Compare prices between types and cuts of meat

\begin{tabular}{|c|c|c|c|c|}
\hline 1 & 2 & 3 & 4 & 5 \\
\hline 1 & 2 & 3 & 4 & 5 \\
\hline 1 & 2 & 3 & 4 & 5 \\
\hline 1 & 2 & 3 & 4 & 5 \\
\hline 1 & 2 & 3 & 4 & 5 \\
\hline 1 & 2 & 3 & 4 & 5 \\
\hline 1 & 2 & 3 & 4 & 5 \\
\hline
\end{tabular}

7. Indicate your degree of agreement with the following sentences, ticking the corresponding number: (1-Totally disagree; 2-disagree; 3-neither agree nor disagree; 4-agree; 5-totally agree)

"What we eat contribute
for climate change"
"Eating less meat is good
for the environment"
"I want to reduce meat
consumption for the sake
of the environment"

\begin{tabular}{|l|l|l|l|l|}
\hline 1 & 2 & 3 & 4 & 5 \\
\hline 1 & 2 & 3 & 4 & 5 \\
\hline 1 & 2 & 3 & 4 & 5 \\
\hline
\end{tabular}

\section{Characterisation of respondent:}

\begin{tabular}{|c|c|c|c|}
\hline & & & \\
\hline Gender: & Feminine & Masculine & \\
\hline Age: & $18-31$ & $32-49$ & 50 or more \\
\hline Household: & $1-3$ elements & 4-6 elements & 7 or more \\
\hline $\begin{array}{l}\text { Resides } \\
\text { in: }\end{array}$ & Urban Area & Non-urban Area & \\
\hline Ocupation: & & & \\
\hline Nationality: & Portuguese & Other & \\
\hline
\end{tabular}

\section{References}

1. Whitnall, T.; Pitts, N. Global Trends in Meat Consumption; ABARE (Australian Bureau of Agricultural and Resource Economics): Canberra, Australia, 2019; Volume 9, pp. 96-99.

2. Figueiredo, C.; Azeiteiro, U.M.; García-Vinuesa, A.; Carvalho, S.C. Campus Decarbonization: Students' Perceptions for Reducing Meat Consumption in a Portuguese University. Sustainability 2021, 13, 6048. [CrossRef]

3. Schleenbecker, R.; Hamm, U. Consumers' perception of organic product characteristics. A review. Appetite 2013, 71, 420-429. [CrossRef] [PubMed]

4. Willer, H.L.J.; Kilcher, L. The World of Organic Agriculture. Statistics Emergerging Trends 2011; Research Institute of Organic Agriculture (FiBL) and IFOAM-Organics International: Frick, Switzerland, 2011; Volume 11, pp. $26-32$.

5. Willer, H.; Schlatter, B.; Trávníček, J.; Kemper, L.; Lernoud, J. The World of Organic Agriculture. Statistics and Emerging Trends 2020, 21st ed.; Research Institute of Organic Agriculture (FiBL) and IFOAM-Organics International: Frick, Switzerland, 2020.

6. Cruz, M. Comportamento e Perfil do Consumidor de Alimentos Biológicos em Portugal; Instituto Superior de Agronomia: Lisbon, Portugal, 2011.

7. Galli, A.; Moreno Pires, S.; Iha, K.; Alves, A.A.; Lin, D.; Mancini, M.S.; Teles, F. Sustainable food transition in Portugal: Assessing the Footprint of dietary choices and gaps in national and local food policies. Sci. Total Environ. $2020,749,141307$. [CrossRef] [PubMed] 
8. Coutinho, P.; Simões, M.; Pereira, C.; Paiva, T. Sustainable Local Exploitation and Innovation on Meat Products Based on the Autochthonous Bovine Breed Jarmelista. Sustainability 2021, 13, 2515. [CrossRef]

9. Kotler, P.; Armstrong, G.; Harris, L.C.; Piercy, N. Principles of Marketing; Pearson: Harlow, UK, 2017.

10. Qazzafi, S. Consumer Buying Decision Process Toward Products. Int. J. Sci. Res. Eng. Dev. 2019, 2, 130-134.

11. Szmigin, I.P.M. Consumer Behaviour, 2nd ed.; Oxford University Press: Glasgow, UK, 2018.

12. Font-i-Furnols, M.; Guerrero, L. Consumer preference, behavior and perception about meat and meat products: An overview. Meat Sci. 2014, 98, 361-371. [CrossRef] [PubMed]

13. Fishbein, M.; Ajzen, I. Belief, Attitude, Intention and Behaviour: An Introduction to Theory and Research; Addison-Wesley: Boston, MA, USA, 1975; Volume 27.

14. Claret, A.; Guerrero, L.; Ginés, R.; Grau, A.; Hernández, M.D.; Aguirre, E.; Peleteiro, J.B.; Fernández-Pato, C.; RodríguezRodríguez, C. Consumer beliefs regarding farmed versus wild fish. Appetite 2014, 79, 25-31. [CrossRef]

15. Guerrero, L.; Claret, A.; Rodriguez, P.; Hernández, F.; Dalmau, A. Actitud, creencias y expectativas de los consumidores españoles frente a la castración (quirúrgica e inmunocastración) y el bienestar animal porcino. In Proceedings of the VII World Congress of Dry-Dured Ham, Ourique, Portugal, 28-31 May 2013.

16. Troy, D.J.; Kerry, J.P. Consumer perception and the role of science in the meat industry. Meat Sci. 2010, 86, 214-226. [CrossRef] [PubMed]

17. Kubberod, E.; Ueland, Ø.; Rødbotten, M.; Westad, F.; Risvik, E. Gender Specific Preferences and Attitudes Towards Meat. Food Qual. Prefer. 2002, 13, 285-294. [CrossRef]

18. Povey, R.; Wellens, B.; Conner, M. Attitudes towards following meat, vegetarian and vegan diets: An examination of the role of ambivalence. Appetite 2001, 37, 15-26. [CrossRef]

19. Berndsen, M.; Pligt, J. Risks of meat: The relative impact of cognitive, affective and moral concerns. Appetite 2005, 44, 195-205. [CrossRef] [PubMed]

20. Grunert, K.G. Future trends and consumer lifestyles with regard to meat consumption. Meat Sci. 2006, 74, 149-160. [CrossRef] [PubMed]

21. MacLeod, C.M. Directed forgetting. Citeseer 1998, 1-57, 1-57.

22. Trienekens, J.; Wognum, N.; Beulens, A.; Van der Vorst, J. Transparency in complex dynamic food supply chains. Adv. Eng. Inform. 2012, 26, 55-65. [CrossRef]

23. Verbeke, W.; Pérez-Cueto, F.J.; Barcellos, M.D.; Krystallis, A.; Grunert, K.G. European citizen and consumer attitudes and preferences regarding beef and pork. Meat Sci. 2010, 84, 284-292. [CrossRef]

24. Luning, P.A.; Marcelis, W.J.; Jongen, W.M. Food Quality Management: A Techno-Managerial Approach; Wageningen Pers: Wageningen, The Netherlands, 2002.

25. Henchion, M.; McCarthy, M.; Resconi, V.C.; Troy, D. Meat consumption: Trends and quality matters. Meat Sci. 2014, 98, 561-568. [CrossRef]

26. Broom, D.M.; Galindo, F.A.; Murgueitio, E. Sustainable, efficient livestock production with high biodiversity and good welfare for animals. Proc. R. Soc. B Biol. Sci. 2013, 280, 20132025. [CrossRef]

27. Tedeschi, L.O.; Muir, J.P.; Riley, D.G.; Fox, D.G. The role of ruminant animals in sustainable livestock intensification programs. Int J. Sustain. Dev. World Ecol. 2015, 22, 452-465. [CrossRef]

28. Fontes, M.A.; Pinto, A.S.; Lemos, J.P. Qualidade na carne de bovino: Atributos e percepção. Rev. Port. De Ciências Veterinárias 2011, 110, 577-580.

29. Schnettler, B.; Vidal, R.; Silva, R.; Vallejos, L.; Sepúlveda, N. Consumer willingness to pay for beef meat in a developing country: The effect of information regarding country of origin, price and animal handling prior to slaughter. Food Qual. Prefer. 2009, 20, 156-165. [CrossRef]

30. Kodinariya, T.M.; Makwana, P.R. Review on Determining Number of Cluster in K-Means Clustering. Int. J. Adv. Res. Computer Sci. Manag. Stud. 2013, 1, 90-95.

31. Piazza, J.; Ruby, M.B.; Loughnan, S.; Luong, M.; Kulik, J.; Watkins, H.M.; Seigerman, M. Rationalizing meat consumption. The 4Ns. Appetite 2015, 91, 114-128. [CrossRef] [PubMed]

32. Schnettler, B.; Ruiz, D.; Sepúlveda, O.; Sepúlveda, N. Importance of the country of origin in food consumption in a developing country. Food Qual. Prefer. 2008, 19, 372-382. [CrossRef]

33. Scozzafava, G.; Corsi, A.M.; Casini, L.; Contini, C.; Loose, S.M. Using the animal to the last bit: Consumer preferences for different beef cuts. Appetite 2016, 96, 70-79. [CrossRef]

34. Merlino, V.M.; Borra, D.; Verduna, T.; Massaglia, S. Household Behavior with Respect to Meat Consumption: Differences between Households with and without Children. Vet. Sci. 2017, 4, 53. [CrossRef]

35. Ngapo, T.; Varela, D.B.; Lozano, M.R. Mexican consumers at the point of meat purchase. Beef choice. Meat Sci. 2017, 134, 34-43. [CrossRef]

36. Webb, E.C.; O'Neill, H.A. The animal fat paradox and meat quality. Meat Sci. 2008, 80, 28-36. [CrossRef]

37. Ellies-Oury, M.-P.; Lee, A.; Jacob, H.; Hocquette, J.-F. Meat consumption-What French consumers feel about the quality of beef? Ital. J. Anim. Sci. 2019, 18, 646-656. [CrossRef]

38. Eldesouky, A.; Mesias, F.J.; Escribano, M. Consumer Assessment of Sustainability Traits in Meat Production. A Choice Experiment Study in Spain. Sustainability 2020, 12, 4093. [CrossRef] 
39. Njisane, Y.Z.; Muchenje, V. Farm to abattoir conditions, animal factors and their subsequent effects on cattle behavioural responses and beef quality-A review. Asian-Australas J. Anim. Sci 2017, 30, 755-764. [CrossRef]

40. Cheah, I.; Sadat Shimul, A.; Liang, J.; Phau, I. Drivers and barriers toward reducing meat consumption. Appetite 2020, 149 , 104636. [CrossRef] [PubMed]

41. Arnaudova, M.; Brunner, T.A.; Götze, F. Examination of students' willingness to change behaviour regarding meat consumption Meat Sci. 2022, 184, 108695. [CrossRef]

42. Hartmann, C.; Lazzarini, G.; Funk, A.; Siegrist, M. Measuring consumers' knowledge of the environmental impact of foods. Appetite 2021, 167, 105622. [CrossRef] [PubMed]

43. Gorissen, K.; Weijters, B. The negative footprint illusion: Perceptual bias in sustainable food consumption. J. Environ. Psychol. 2016, 45, 50-65. [CrossRef]

44. Austgulen, M.H.; Skuland, S.E.; Schjøll, A.; Alfnes, F. Consumer Readiness to Reduce Meat Consumption for the Purpose of Environmental Sustainability: Insights from Norway. Sustainability 2018, 10, 3058. [CrossRef]

45. Tobler, C.; Visschers, V.H.M.; Siegrist, M. Eating green. Consumers' willingness to adopt ecological food consumption behaviors. Appetite 2011, 57, 674-682. [CrossRef] [PubMed]

46. Pohjolainen, P.; Tapio, P.; Vinnari, M.; Jokinen, P.; Räsänen, P. Consumer consciousness on meat and the environment-Exploring differences. Appetite 2016, 101, 37-45. [CrossRef]

47. Randler, C.; Adan, A.; Antofie, M.M.; Arrona-Palacios, A.; Candido, M.; Boeve-de Pauw, J.; Chandrakar, P.; Demirhan, E.; Detsis, V.; Di Milia, L.; et al. Animal Welfare Attitudes: Effects of Gender and Diet in University Samples from 22 Countries. Animals 2021, 11, 1893. [CrossRef]

48. Miranda-de la Lama, G.C.; Estévez-Moreno, L.X.; Sepúlveda, W.S.; Estrada-Chavero, M.C.; Rayas-Amor, A.A.; Villarroel, M.; María, G.A. Mexican consumers' perceptions and attitudes towards farm animal welfare and willingness to pay for welfare friendly meat products. Meat Sci. 2017, 125, 106-113. [CrossRef]

49. Estévez-Moreno, L.X.; María, G.A.; Sepúlveda, W.S.; Villarroel, M.; Miranda-de la Lama, G.C. Attitudes of meat consumers in Mexico and Spain about farm animal welfare: A cross-cultural study. Meat Sci. 2021, 173, 108377. [CrossRef]

50. Sonoda, Y.; Oishi, K.; Chomei, Y.; Hirooka, H. How do human values influence the beef preferences of consumer segments regarding animal welfare and environmentally friendly production? Meat Sci. 2018, 146, 75-86. [CrossRef] [PubMed]

51. Blanc, S.; Massaglia, S.; Borra, D.; Mosso, A.; Merlino, V.M. Animal welfare and gender: A nexus in awareness and preference when choosing fresh beef meat? Ital. J. Anim. Sci. 2020, 19, 410-420. [CrossRef]

52. Alonso, M.E.; González-Montaña, J.R.; Lomillos, J.M. Consumers' Concerns and Perceptions of Farm Animal Welfare. Animals 2020, 10, 385. [CrossRef] [PubMed]

53. Loewen, S.; Gonulal, T. Exploratory Factor Analysis and Principal Components Analysis. In Advancing Quantitative Methods in Second Language Research, 1st ed.; Plonsky, L., Ed.; Routledge: New York, NY, USA, $2015 ;$ pp. $182-212$.

54. Luzio, J.P.P.; Lemke, F. Exploring green consumers' product demands and consumption processes. Eur. Bus. Rev. 2013, 25, 281-300. [CrossRef]

55. Brito, R.A.C.d.C. Alimentação Saudável: Níveis de Consumo de Alimentos Orgânicos em Portugal; Instituto Universitário de Lisboa: Lisboa, Portugal, 2018.

56. Bryła, P. Organic food consumption in Poland: Motives and barriers. Appetite 2016, 105, 737-746. [CrossRef]

57. Żakowska-Biemans, S. Polish consumer food choices and beliefs about organic food. Br. Food J. 2011, 113, 122-137. [CrossRef]

58. Cubero Dudinskaya, E.; Naspetti, S.; Arsenos, G.; Caramelle-Holtz, E.; Latvala, T.; Martin-Collado, D.; Orsini, S.; Ozturk, E.; Zanoli, R. European Consumers' Willingness to Pay for Red Meat Labelling Attributes. Animals 2021, 11, 556. [CrossRef]

59. Siegrist, M.; Hartmann, C. Impact of sustainability perception on consumption of organic meat and meat substitutes. Appetite 2019, 132, 196-202. [CrossRef]

60. Araújo, J.P.; Cerqueira, J.; Vaz, P.S.; Pinto de Andrade, L.; Várzea Rodrigues, J.; Rodrigues, A.M. Extensive beef cattle production in Portugal. In Proceedings of the International Workshop New updates in Animal Nutrition, Natural Feeding Sources and Environmental Sustainability, Arzachena, Sardinia, Italy, 5-6 May 2014.

61. Chander, M.; Subrahmanyeswari, B.; Mukherjee, R.; Kumar, S. Organic livestock production: An emerging opportunity with new challenges for producers in tropical countries. Rev. Sci. Tech. Off. Int. Epiz 2011, 30,969-983. [CrossRef]

62. Budhathoki, M.; Pandey, S. Intake of Animal-Based Foods and Consumer Behaviour towards Organic Food: The Case of Nepal. Sustainability 2021, 13, 12795. [CrossRef]

63. Lambarraa-Lehnhardt, F.; Ihle, R.; Elyoubi, H. How Successful Is Origin Labeling in a Developing Country Context? Moroccan Consumers' Preferences toward Local Products. Sustainability 2021, 13, 8433. [CrossRef] 